\title{
RESEARCH PAPER \\ Effects of wine grape cultivar, application conditions and the winemaking process on the dissipation of six pesticides
}

\author{
Claudio Alister ${ }^{1,5}$, Manuel Araya ${ }^{1}$, Jose E. Morandé2 ${ }^{2}$, Christian Volosky ${ }^{3}$, \\ Jorge Saavedra ${ }^{4}$, Andrés Cordova $^{4}$ and Marcelo Kogan ${ }^{5}$ \\ ${ }^{1}$ Escuela de Ciencias Agrícolas. Universidad Viña del Mar. Agua Santa 7055, Viña del Mar, Chile. \\ ${ }^{2}$ Jubaea Limitada, Camino El Cerrillo 2375, Buin, Chile. \\ ${ }^{3}$ ANASAC Chile S.A. Almirante Pastene 300, Santiago, Chile. \\ ${ }^{4}$ DATAChem Agrofood Group. Escuela de Ingeniería de Alimentos. Pontificia Universidad Católica de \\ Valparaíso. Waddington 716, Valparaíso, Chile. \\ ${ }^{5}$ SIDAL Limitada, Lo Orozco, Casablanca, Chile.
}

\begin{abstract}
C. Alister, M. Araya, J.E. Morandé, C. Volosky, J. Saavedra, A. Cordova, and M. Kogan. 2014. Effects of wine grape cultivar, application conditions and the winemaking process on the dissipation of six pesticides. Cien. Inv. Agr. 41(3):375-386. Pesticide residue in primary products is an important issue for producers and consumers, even though little information is available on the effect of application conditions on residue persistence and the transfer to primary elaborated products. During the 2012 season, field and laboratory studies were conducted to determine the dissipation of lambda-cyhalothrin, buprofezin, pyrimethanil, tebuconazole, imidacloprid and acetamiprid in Sauvignon blanc and Pinot Noir cultivars and their residue dynamics during the winemaking process. Half-life values $\left(\mathrm{DT}_{50}\right)$ for each pesticide applied alone and as a tank mix of all pesticides were similar and had averages of 6.4, 14.0, 19.7, 26.0, 14.5 and 13.4 days for lambda-cyhalothrin, buprofezin, pyrimethanil, tebuconazole, imidacloprid and acetamiprid, respectively. The grape cultivar did not affect pesticide $\mathrm{DT}_{50}$. All pesticides were transferred from the raw material (grape) to red and white wines except lambdacyhalothrin. The transfer factors of buprofezin, tebuconazole pyrimethanil, imidacloprid and acetamiprid ranged from 3 to $23 \%$ in red wine and 9 to $30 \%$ in white wine. Alcoholic fermentation, pressing (through pomace) and malolactic fermentation were the steps in which the greatest residue losses occurred in red wine, whereas pressing (through the grape and stem), alcoholic fermentation and clarification with bentonite had the greatest residue loss in white wine. In both cases, bottled wine showed substantial residue reduction after ten months.
\end{abstract}

Key words: Pre-harvest interval, residues, transfer factor, wine

\section{Introduction}

The presence of a residue in wine leads to rejection by the consumers, even with concentrations

Received April 24, 2014. Accepted September 5, 2014. Corresponding author: calister@uvm.cl below the maximum residue limits (MRLs). According to studies performed in Italy, approximately $30 \%$ of foods showed residues below MRLs (Pasarella et al., 2009). The main products that provide residues to a person's diet were fruits and wine, comprising 77 and $15 \%$ of intake residues, respectively (Lorenzini, 2007). 
For this reason, all agricultural productive chains, including wine production, require scientific information related to residue dissipation to avoid food contamination.

The main factors that regulate fruit pesticide persistence include plant species, cultivar, pesticide formulation, application methods, climatic conditions, and pesticide physico-chemical properties and industrial processes (Cabras et al., 1997; Cabras and Angioni, 2000; Mandal et al., 2010). However, information related to the interaction between these different factors and how each factor affects field dissipation, and therefore the residue level in the processing product, is highly variable (Banerjee et al., 2006; Pasarella et al., 2009; Gonzalez-Rodriguez et al., 2009; Liu et al., 2012).

Because of pest resistance in the field, pesticides are normally applied as tank mixtures. However, the effects of the above mentioned factors in pesticide dissipation are not well understood. For these reasons, the aim of this study was to determine the field dissipation of pesticides regularly used on wine grape cultivars (Sauvignon Blanc and Pinot Noir) and to identify the steps of the winemaking process that may affect pesticide residue persistence.

\section{Materials and methods}

\section{Pesticide field dissipation studies}

The present study was conducted from February to April 2012 in a vineyard located at Casablanca Valley, Valparaiso region, Chile (Latitude 3317' S and Longitude $71^{\circ} 24^{\prime} \mathrm{W}$ ). Wine grape cultivars corresponded to Sauvignon Blanc and Pinot Noir. Two 40-m rows of each cultivar received an individual application of each of the formulated pesticides (Table 1); additionally, two rows without pesticide application (untreated grapes) were left as a control experiment, and in the case of the Sauvignon Blanc cultivar, two rows were treated by a tank mixture containing all six pesticides. Each treatment was separated by four rows that acted as a "buffer area" to avoid contamination by drift. The formulated pesticides, which included lambda-cyhalothrin, buprofezin, pyrimethanil, tebuconazole, imidacloprid and acetamiprid, were applied using a spray gun (GunJet $\AA$ ) equipped with an Albuz ATR 80 nozzle at 6 bar, achieving an application volume and the rates shown in Table 1.

Grape berry samples were collected in each experimental plot at 0 (after application dryness), 2, 9, 20, 30, 40 and 50 days after application (DAA) following a random sampling in each

Table 1. Pesticides applied to Sauvignon Blanc and Pinot Noir grapes.

\begin{tabular}{|c|c|c|c|c|c|}
\hline \multicolumn{2}{|c|}{ Pesticide $^{1}$} & \multicolumn{2}{|c|}{ Sauvignon Blanc } & \multicolumn{2}{|c|}{ Pinot Noir } \\
\hline Active ingredient & Formulation & $\begin{array}{l}\text { Application } \\
\text { volume } \\
\left(\mathrm{L} \mathrm{ha}^{-1}\right)\end{array}$ & $\begin{array}{c}\text { Formulated } \\
\text { pesticide rate } \\
\left.(\mathrm{mL} \mathrm{ha})^{-1}\right)\end{array}$ & $\begin{array}{l}\text { Application } \\
\text { volume } \\
\left(\mathrm{L} \mathrm{ha}^{-1}\right)\end{array}$ & $\begin{array}{l}\text { Formulated } \\
\text { pesticide rate } \\
\left(\mathrm{mL} \mathrm{h}^{\mathrm{a}-1}\right)\end{array}$ \\
\hline Lambda-cyhalothrin & Concentrated emulsion (EC) & $1,600.9$ & 249.4 & $1,162.9$ & 181.1 \\
\hline Buprofezin & Wettable powder (WP) & $1,726.4$ & $1,726.4$ & $1,226.0$ & $1,226.0$ \\
\hline Pyrimethanil & $\begin{array}{l}\text { Concentrated suspension } \\
\text { (SC) }\end{array}$ & $1,792.8$ & $2,686.2$ & $1,337.7$ & $2,006.6$ \\
\hline Tebuconazole & Water emulsion (EW) & $1,635.8$ & $3,052.4$ & $1,444.4$ & $2,695.2$ \\
\hline Imidacloprid & Wettable powder (WP) & $1,745.5$ & 523.6 & $1,529.7$ & 458.9 \\
\hline Acetamiprid & Wettable powder (WP) & $1,721.7$ & 258.2 & $1,463.7$ & 219.5 \\
\hline
\end{tabular}

${ }^{1} \mathrm{~A}$ tank mixture of all them was applied at the same commercial pesticide rate and at an application volume of 1,655.6 $\mathrm{L} \mathrm{ha}^{-1}$. 

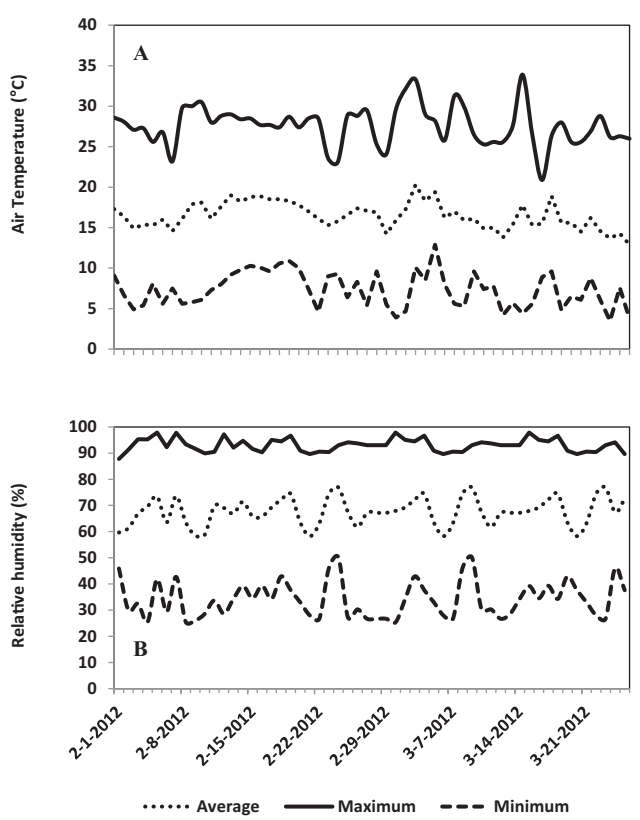

Figure 1. Principal climatic conditions during the study period. A) Maximum, minimum and average air temperature and B) Maximum, minimum and average relative humidity. (Application date: January $1^{\text {st }}$ ).

replication (three for each treatment and cultivar). Samples of $\pm 600 \mathrm{~g}$ were kept in a plastic bag at $4 \pm 1^{\circ} \mathrm{C}$ until they were transported to the laboratory, where they were maintained at $-18{ }^{\circ} \mathrm{C}$ until residue analysis. The climatic conditions are shown in the Figure 1.

\section{Vinification studies}

Seventy-two hours after the Pinot noir and Sauvignon blanc grape cultivars were sprayed with the pesticides treatments, $75 \mathrm{~kg}$ of each cultivar were harvested and placed in a micro-cellar at the Universidad Viña del Mar. The Pinot noir grapes were crushed, de-stemmed, and transferred to a $200 \mathrm{~L}$ stainless steel tank, and $2 \mathrm{mg} \mathrm{L}^{-1}$ of $\mathrm{SO}_{2}$ (sodium metabisulfite) was added. At the end of alcoholic fermentation, the must was separated into free-run wine, press wine and pomace. The free-run and press wines obtained were mixed and transferred to a $50 \mathrm{~L}$ stainless steel tank to complete the malolactic fermentation. Afterwards, $2 \mathrm{mg} \mathrm{L}^{-1}$ of $\mathrm{SO}_{2}$ (sodium metabisulfite) were added, and the wine filtered through a $0.2 \mu \mathrm{m}$ fiberglass filter and bottled.

In the case of the Sauvignon blanc, the grape bunches were pressed, and the obtained juice was transferred to a $50 \mathrm{~L}$ stainless steel tank. At the end of the alcoholic fermentation, the wine was clarified using bentonite $\left(0.45 \mathrm{~g} \mathrm{~L}^{-1}\right)$ and $8 \mathrm{mg} \mathrm{L}^{-1}$ of $\mathrm{SO}_{2}$ (sodium metabisulfite), stabilized at $4{ }^{\circ} \mathrm{C}$ for 5 days, filtered through a $0.2 \mathrm{~mm}$ fiber glass filter and bottled.

Each vinification process (red and white) was performed in duplicate, and samples for residue analysis were taken in each of the vinification steps, including a final sample after 10 months from the storage bottles, which were stored in darkness at $20{ }^{\circ} \mathrm{C}$ and $80 \%$ relative humidity.

\section{Pesticide extraction and analysis}

In the cases of grape berries, stems and pomace, $\pm 600 \mathrm{~g}$ samples were homogenized using a Grindomix Knife Mill, and sub samples of $10 \mathrm{~g}$ were taken for analysis. In the case of wine samples, $10 \mathrm{~g}$ were taken. All samples were placed in 50 $\mathrm{mL}$ plastic tubes to which $20 \mathrm{~mL}$ of acetonitrile/ methanol was added. After agitation, the plastic tubes were placed into an Ultrasonic bath for 10 min, $4 \mathrm{~g} \mathrm{MgSO}_{4}$ and $1 \mathrm{~g} \mathrm{NaCl}$ were added, and the tubes were shaken. Finally, all samples were centrifuged at 4,500 rpm for $5 \mathrm{~min}$, and an aliquot of $15 \mathrm{~mL}$ was taken from each centrifuged sample and concentrated to dryness in a rotary evaporator, re-suspended in $2 \mathrm{~mL}$ ethyl acetate, transferred to a $1.5 \mathrm{~mL}$ glass vial, and analyzed using high-pressure liquid chromatography (Hitachi LaChrom Elite Model L-2300) with a diode array detector (Hitachi LaChrom Elite Model L-2450) or gas chromatography (Shimadzu Model GC-2010) with a mass detector (Shimadzu GCMS-QP 2010 Plus), depending on the analite.

Lambda-cyhalothrin, buprofezin, pyrimethanil and tebuconazole were quantified through GC- 
MS equipped with a RTX ${ }^{\circledR} 5$-MS $30 \mathrm{~m} \times 0.25$ $\mathrm{mm} \times 0.25 \mathrm{~mm}$ column. The gas carrier was

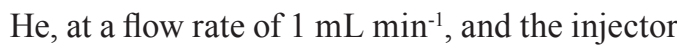
temperature was $250{ }^{\circ} \mathrm{C}$. The samples $(2 \mu \mathrm{L})$ were injected into the autosampler in a splitless mode. The oven temperature was $70^{\circ} \mathrm{C}$ for $1 \mathrm{~min}$, increased to $150{ }^{\circ} \mathrm{C}$ at $25^{\circ} \mathrm{C} \mathrm{min}{ }^{-1}$, followed by an increase to $200{ }^{\circ} \mathrm{C}$ at $3{ }^{\circ} \mathrm{C} \mathrm{min}^{-1}$, and finally raised to $280^{\circ} \mathrm{C}$ at $8{ }^{\circ} \mathrm{C} \mathrm{min}^{-1}$. Ion Mass $(\mathrm{m} / \mathrm{z})$ pesticide quantifications were 181 for lambdacyhalothrin (time retention: $29.21 \mathrm{~min}$ ); 105 for buprofezin (time retention: $24.06 \mathrm{~min}$ ); 198 for pyrimethanil (time retention: $13.845 \mathrm{~min}$ ); and 125 for tebuconazole (time retention: $23.183 \mathrm{~min}$ ). The detection limits were $0.0029 \mathrm{mg} \mathrm{kg}^{-1}$ for lambdacyhalothrin, $0.0242 \mathrm{mg} \mathrm{kg}^{-1}$ for buprofezin, 0.0114 $\mathrm{mg} \mathrm{kg}^{-1}$ for pyrimethanil, and $0.0086 \mathrm{mg} \mathrm{kg}^{-1}$ for tebuconazole, and the recoveries were 91.0, 108.0, 88.0 and $102.1 \%$, respectively.

Imidacloprid and acetamiprid were quantified through HLPC-DAD. The HPLC unit was equipped with a Waters ${ }^{\circledR}$ Symmetyl Shield RP-8 $5 \mu \mathrm{m}$ 3.9-150 mm column and Chromolith RP-18e 5-4.6 $\mathrm{mm}$ pre-column. The liquid phase used was water-acetonitrile at a flow rate of $1 \mathrm{~mL} \mathrm{~min}^{-1}$ with a gradient from water-acetonitrile $(95 / 5 \mathrm{v} / \mathrm{v})$ for 1 $\mathrm{min}$, then to $85 / 15(\mathrm{v} / \mathrm{v})$ for $5 \mathrm{~min}$, to $60 / 40(\mathrm{v} / \mathrm{v})$ for $2 \mathrm{~min}$, to 20/80 (v/v) for $9 \mathrm{~min}$, and kept at $95 / 5(\mathrm{v} / \mathrm{v})$ for $14 \mathrm{~min}$. The column temperature was $35^{\circ} \mathrm{C}$, and the injection volume was $10 \mu \mathrm{L}$. The detector (Hitachi model Elite LaChrom L-2450) settings were $270 \mathrm{~nm}$ for imidacloprid (retention time: $12.29 \mathrm{~min}$ ) and $247 \mathrm{~nm}$ for acetamiprid (retention time: $21.487 \mathrm{~min}$ ). The recoveries of the spiked samples were 99.3 and $100.8 \%$ for imidacloprid and acetamiprid, and the detection limits were $0.0112 \mathrm{mg} \mathrm{kg}^{-1}$ and $0.0199 \mathrm{mg} \mathrm{kg}^{-1}$, respectively.

\section{Data analysis}

Field grape berry pesticide dissipation results were fitted to a first-order kinetic model [1] using nonlinear regression analysis, defined by the following equations:

$$
\begin{gathered}
C=C o * \exp (-k * t) \\
D T_{50}=\operatorname{Ln} 2 / k \\
D T_{90}=\operatorname{Ln} 9 / k
\end{gathered}
$$

where $C\left(\mathrm{mg} \mathrm{kg}^{-1}\right)$ is the grape pesticide concentration at time $t$ (days), $C o\left(\mathrm{mg} \mathrm{kg}^{-1}\right)$ is the initial pesticide concentration, and $k$ (days-1) is a first-order dissipation rate that determines the slope of the curve. The model prediction capacity was calculated using a Mean Absolute Error (MAE). The 50\% dissipation time (DT50) and 90\% dissipation time (DT90) were estimated using equations 2 and 3 .

Residue results from the winemaking process were explored with Principal Component Analysis (PCA) and modeled by Partial Least Square Regression (PLS) and Ridge Regression. The data were sorted into a two-dimensional matrix array, with one dimension as the residue transferred rate and the other dimension as the physico-chemical pesticide properties.

\section{Results and discussion}

\section{Pesticide grape berry dissipation}

Pesticide field dissipation was well described by a first-order exponential model for all study conditions (individual applications, tank mixture of all pesticides and vine grape varieties) (Table 2). The use of an $n>1$-order exponential model did not show a significant improvement (data not shown), which is consistent with other field studies (e.g., Pasarella et al., 2009; Liang et al., 2012). Several authors have reported a higher dissipation rate in the field during the first week after application, followed by a slow dissipation rate during the second or third weeks for table and wine grapes (Cabras et al., 2001; Mandal et al., 2010; Liu et al., 2012). However, in this study, dissipation rates were stable during the entire study period (approximately six weeks). Only 
Table 2. First-order dissipation model parameters for six pesticides applied to Sauvignon Blanc and Pinot Noir wine grape berries. Parentheses denote $95 \%$ confidence intervals.

\begin{tabular}{|c|c|c|c|c|c|c|c|c|}
\hline \multirow[b]{2}{*}{ Pesticides } & \multirow[b]{2}{*}{$\begin{array}{l}\text { Application } \\
\text { Condition }^{1}\end{array}$} & \multicolumn{4}{|c|}{ Parameters $^{1}$} & \multirow{2}{*}{$\begin{array}{c}\text { Residues at } \\
49 \text { DAA }\end{array}$} & \multirow[b]{2}{*}{$\mathrm{MAE}^{4}$} & \multirow[b]{2}{*}{$\mathrm{R}^{2}$} \\
\hline & & Co & $K$ & $D T_{50}{ }^{3}$ & $D T_{90}{ }^{3}$ & & & \\
\hline \multirow[t]{3}{*}{ Lambda-cyhalothrin } & Individually S.B & $0.022(0.019-0.024)$ & $0.048(0.044-0.053)$ & $14.4 \pm 1.4$ & $45.5 \pm 4.4$ & $0.003 \pm 0.003$ & 0.264 & 0.93 \\
\hline & Individually P.N & $0.024(0.021-0.027)$ & $0.045(0.039-0.051)$ & $15.3 \pm 2.0$ & $48.6 \pm 6.5$ & $0.004 \pm 0.003$ & 0.334 & 0.88 \\
\hline & Mixed S.B & $0.020(0.017-0.022)$ & $0.038(0.028-0.052)$ & $18.5 \pm 3.3$ & $58.6 \pm 10.5$ & $0.003 \pm 0.002$ & 0.239 & 0.93 \\
\hline \multirow[t]{3}{*}{ Buprofezin } & Individually S.B & $3.711(3.321-4.101)$ & $0.064(0.053-0.069)$ & $10.8 \pm 0.9$ & $34.3 \pm 2.9$ & $0.259 \pm 0.155$ & 0.302 & 0.95 \\
\hline & Individually P.N & $3.999(3.626-4.372)$ & $0.073(0.056-0.090)$ & $9.8 \pm 1.4$ & $31.2 \pm 4.3$ & $0.372 \pm 0.167$ & 0.404 & 0.94 \\
\hline & Mixed S.B & $2.970(2.601-3.339)$ & $0.053(0.047-0.058)$ & $13.2 \pm 1.3$ & $41.7 \pm 3.9$ & $0.259 \pm 0.121$ & 0.316 & 0.92 \\
\hline \multirow[t]{3}{*}{ Pyrimethanil } & Individually S.B & $3.018(2.642-3.393)$ & $0.035(0.031-0.038)$ & $19.8 \pm 1.7$ & $62.7 \pm 5.6$ & $0.535 \pm 0.077$ & 0.192 & 0.94 \\
\hline & Individually P.N & $2.696(2.362-3.030)$ & $0.033(0.030-0.037)$ & $20.7 \pm 2.2$ & $65.6 \pm 6.9$ & $0.506 \pm 0.078$ & 0.231 & 0.91 \\
\hline & Mixed S.B & $3.111(2.760-3.462)$ & $0.035(0.032-0.038)$ & $19.6 \pm 1.8$ & $62.2 \pm 5.3$ & $0.505 \pm 0.114$ & 0.196 & 0.93 \\
\hline \multirow[t]{3}{*}{ Tebuconazole } & Individually S.B & $3.363(2.994-3.731)$ & $0.030(0.022-0.038)$ & $24.3 \pm 3.8$ & $77.2 \pm 12.2$ & $0.913 \pm 0.212$ & 0.137 & 0.83 \\
\hline & Individually P.N & $3.317(2.931-3.702)$ & $0.026(0.024-0.030)$ & $25.2 \pm 2.5$ & $79.9 \pm 7.8$ & $0.811 \pm 0.267$ & 0.168 & 0.92 \\
\hline & Mixed S.B & $3.446(3.181-3.711)$ & $0.026(0.023-0.027)$ & $26.9 \pm 2.1$ & $85.5 \pm 6.7$ & $0.902 \pm 0.123$ & 0.117 & 0.95 \\
\hline \multirow[t]{3}{*}{ Imidacloprid } & Individually S.B & $0.600(0.564-0.635)$ & $0.054(0.047-0.062)$ & $13.0 \pm 1.1$ & $41.2 \pm 3.3$ & $0.017 \pm 0.031$ & 0.218 & 0.97 \\
\hline & Individually P.N & $0.742(0.677-0.807)$ & $0.050(0.040-0.060)$ & $14.4 \pm 1.7$ & $45.5 \pm 5.4$ & $0.057 \pm 0.051$ & 0.076 & 0.93 \\
\hline & Mixed S.B & $0.748(0.659-0.836)$ & $0.043(0.038-0.047)$ & $16.2 \pm 1.6$ & $51.2 \pm 5.1$ & $0.090 \pm 0.045$ & 0.248 & 0.92 \\
\hline \multirow[t]{3}{*}{ Acetamiprid } & Individually S.B & $0.731(0.657-0.804)$ & $0.060(0.045-0.074)$ & $12.1 \pm 1.7$ & $38.3 \pm 5.5$ & $0.035 \pm 0.061$ & 0.073 & 0.92 \\
\hline & Individually P.N & $0.673(0.612-0.733)$ & $0.046(0.037-0.056)$ & $15.4 \pm 1.9$ & $48.8 \pm 6.0$ & $0.089 \pm 0.030$ & 0.184 & 0.92 \\
\hline & Mixed S.B & $0.675(0.615-0.735)$ & $0.047(0.038-0.057)$ & $15.0 \pm 1.8$ & $47.7 \pm 5.8$ & $0.069 \pm 0.062$ & 0.061 & 0.92 \\
\hline
\end{tabular}

${ }^{1}$ Individually S.B= Each pesticide applied individually to Sauvignon Blanc wine grapes; Individually P.N= Each pesticide applied individually to Pinot Noir wine grapes; Mixed S.B $=$ Six pesticides applied as a tank mixture of all pesticides to Sauvignon Blanc wine grapes.

${ }^{2} \mathrm{Co}=$ Initial fruit pesticide concentration $\left(\mathrm{mg} \mathrm{kg}^{-1}\right) ; \mathrm{k}=$ First-order dissipation constant $\left(\right.$ days $\left.^{-1}\right)$; DT50 and DT90 = 50\% and $90 \%$ dissipation time (days).

${ }^{3}$ Values are means of three replications $\pm \mathrm{SE}$.

${ }^{4}$ Medium average error.

in the cases of buprofezin and pyrimethanil different dissipation rates were observed, although the higher dissipation rate occurred during the first three weeks.

In general, all pesticides showed detectable residues until the end of the study period (50 DAA). However, considering the MRLs for wine grapes, all pesticides satisfied the most restricted worldwide MRLs, established as follows: Lambdacyhalothrin $=0.01 \mathrm{mg} \mathrm{kg}^{-1}$, buprofezin $=0.3 \mathrm{mg}$ $\mathrm{kg}^{-1}$, pyrimethanil $=2.0 \mathrm{mg} \mathrm{kg}^{-1}$, tebuconazole $=1.0 \mathrm{mg} \mathrm{kg}^{-1}$, imidacloprid $=0.1 \mathrm{mg} \mathrm{kg}^{-1}$ and acetamiprid $=0.05 \mathrm{mg} \mathrm{kg}^{-1}$. In this study, those MRLs were reached at 12, 25, 9, 35, 29 and 49 days, respectively.

Thorbek and Hyder (2006) considered that 50\% of pesticide dissipation is related to physico- chemical properties. However, other factors, such as weather conditions, variety, application techniques and fruit growth stage, could affect pesticide dissipation curves (Benerjee et al., 2006). The results of this study did not show any significant difference in pesticide dissipation whether the pesticides were applied individually or in a tank mixture or between different wine grape cultivars (Table 2).

Lamda-cyhalothrin $\mathrm{DT}_{50}$ values were similar to values reported for apple foliage and fruits (Jun et al., 2008) but higher than those reported for wine grapes (Vitis vinifera) (Benerjee et al., 2006). In the case of wine grapes, the $\mathrm{DT}_{50}$ was between 4.7 and 7.0 days for almost $50 \%$ of the $\mathrm{DT}_{50}$ values obtained in our study. This difference could be explained because applications were made at the end of the fruit growth period, 
in comparison to the mentioned study (Benerjee et al., 2006), in which pesticides were applied at the initial stage of grape berry growth. Similar to lambda-cyhalothrin, buprofezin showed higher dissipation rates than rates reported for other species, such as clementines (Citrus reticulate var. clementina) (Cabras et al., 2001) and wine grapes (Oulkar et al., 2009).

Gabriolotto et al. (2009) found a range between 0.24 and $0.47 \mathrm{mg} \mathrm{kg}^{-1}$ of pyrimethanil residues in wine grape berries at $65 \mathrm{DAA}$, which is consistent with the results of this study (Table 2). Moreover, these authors found the same dissipation rate for pyrimethanil and five other pesticides in Moscatel and Barbera wine grape cultivars. These results are contradictory to those of Angioni et al. (2006), who reported a $\mathrm{DT}_{50}$ of 12 days for table grapes, with an initial deposit of $2.48 \pm 0.9 \mathrm{mg} \mathrm{kg}^{-1}$, in concordance with results presented here. However, Cabras et al. (2001) reported a $\mathrm{DT}_{50}$ of 57 days for the same pesticide in the same species.

In the case of tebuconazole, reported dissipation rates have been variable. Jyot et al. (2010) determined a $\mathrm{DT}_{50}$ value of less than 5 days and no detectable residues at 34 DAA when a mixture of trifloxystrobin + tebuconazole was applied to grape berries. In contrast, Mohapatra et al. (2010) found tebuconazole residues in grape berries at 30 DAA and a $\mathrm{DT}_{50}$ of approximately 20 days after the same mixture was applied. In this study. Tebuconazole $\mathrm{DT}_{50}$ varied between 16.6 and 31.5 days, depending on the types of grape cultivars and pesticides used (Table 2). The residues were approximately $0.876 \pm 0.056$ $\mathrm{mg} \mathrm{kg}^{-1}$ at 49 DAA. This difference between our results and the few reported in the literature could be explained by a dilution effect resulting from fruit growth and possible losses from sunlight photo-degradation and co-distillation (Pasarella et al., 2009).

Acetamiprid and imidacloprid also showed variable results in comparison to the literature. Imidacloprid $\mathrm{DT}_{50}$ varied from 13.0 to 14.4 in Sauvignon Blanc and Pinot Noir, respectively (Table 2), with residues of $0.055 \pm 0.037 \mathrm{mg} \mathrm{kg}^{-1}$ at 49 DAA. A similar dissipation rate was observed by Mohapatra et al. (2011) in wine grape berries, reporting $\mathrm{DT}_{50}$ of 16.6 days and residues of 0.074 $\mathrm{mg} \mathrm{kg}^{-1}$ at 50 DAA. However, Arora et al. (2009) determined residues of $0.14 \mathrm{mg} \mathrm{kg}^{-1}$ at 15 DAA. Acetamiprid dissipation in the present study showed a $\mathrm{DT}_{50} 12$ days longer than that reported by Arora et al. (2009) and Gupta et al. (2005), and residues were detectable up to 49 DAA (Table 3). These substantial differences could be related to sunlight (UV-light) and temperature conditions, factors important for acetamiprid field dissipation (Gupta et al., 2008).

Table 3. Pesticide transfer rate (\%) resulting from both vinification process evaluated before bottling and after bottle storage ( 10 months in darkness at $20 \pm 2{ }^{\circ} \mathrm{C}$ ). Values correspond to the average of two replications \pm standard deviation.

\begin{tabular}{lccccc}
\hline \multirow{2}{*}{ Pesticide } & \multicolumn{4}{c}{ Transfer rate (\%) } \\
\cline { 2 - 3 } & \multicolumn{2}{c}{ Bottled wine } & & \multicolumn{2}{c}{ After storage in bottle } \\
\cline { 2 - 3 } & White wine & Red wine & & White wine & Red wine \\
\hline Lambda-cyhalothrin & $0.0( \pm 0.0)$ & $0.0( \pm 0.0)$ & & $0.0( \pm 0.0)$ & $0.0( \pm 0.0)$ \\
Buprofezin & $10.7( \pm 3.2)$ & $12.0( \pm 0.2)$ & & $2.2( \pm 0.9)$ & $1.8( \pm 0.2)$ \\
Pyrimethanil & $10.4( \pm 2.3)$ & $8.8( \pm 1.6)$ & & $6,3( \pm 1.1)$ & $4.0( \pm 0.7)$ \\
Tebuconazole & $9.0( \pm 2.5)$ & $3.3( \pm 0.1)$ & & $2.5( \pm 1.2)$ & $1.5( \pm 0.1)$ \\
Imidacloprid & $13.9( \pm 3.1)$ & $10.4( \pm 2.0)$ & & $1.2( \pm 1.0)$ & $0.7( \pm 2.0)$ \\
Acetamiprid & $30.4( \pm 9.8)$ & $23.2( \pm 5.1)$ & & $4.5( \pm 3.3)$ & $8.6( \pm 5.1)$ \\
\hline
\end{tabular}


Table 4. Ridge regression to pesticide residue transfer (\%) from grape to wine.

\begin{tabular}{|c|c|c|}
\hline Wine making process & Ridge Regression Model $^{1}$ & $\mathrm{R}^{2}$ \\
\hline White & Transfer $\%=0.039-0.0022 * \operatorname{LogKow}+9.298 \mathrm{E}-5 * S+1.758 \mathrm{E}-3 * W T D_{50}$ & $\begin{array}{l}0.87 \\
(\mathrm{P} \leq 0.0001)\end{array}$ \\
\hline Red & Transfer $\%=0.746-0.00154 * \log K o w+7.969 \mathrm{E}-5 * S+0.252 \mathrm{E}-3 * W T D_{50}$ & $\begin{array}{l}0.80 \\
(\mathrm{P} \leq 0.0001)\end{array}$ \\
\hline
\end{tabular}

${ }^{1} \mathrm{~S}=$ Solubility at $20^{\circ} \mathrm{C} ; W T D_{50}=$ Water half-life.

\section{Pesticide residues during the vinification process}

The transfer percentage from grape berries to wine, for all pesticides studied, was between 0 and $43.9 \%$ in white wine and 0 and $23 \%$ in red wine. However, the transfer rate considering bottled wine after the storage period (ten months at darkness at $20 \pm 2{ }^{\circ} \mathrm{C}$ ) decreased the maximum transfer percentages to 10.4 and $8.6 \%$ for white and red wine, respectively (Table 3 ).

Data from the literature on pesticides transfer from grape berries to wine are variable and dependent on the vinification process and physico-chemical pesticide properties, particularly the lipophilicity (LogKow) and solubility (Cabras et al., 1997; Navarro et al., 1999; Cabras and Angioni, 2000; Agnioni et al., 2003; Gonzalez-Rodriguez et al., 2009).

The PLS and PCA analyses determined that the pesticide residues transfer in both winemaking processes (red and white) depended on the LogKow, solubility and water $\mathrm{DT}_{50}$. The Ridge Regression showed coefficients of $0.87(\mathrm{P} \leq 0.001)$ and 0.80 $(\mathrm{P} \leq 0.001)$ for red and white wine, respectively (Table 4).

In general, less residue removal was found in white grape berry vinification process compared to the red vinification process (Table 3; Figure 2 and 3). Angioni et al. (2011) found more removal of iprovalicarb, indoxacard and boscalid in red wine vinification than in the white wine process. The higher residue removal observed in red wine vinification is in part due to the malolactic fermentation, which reduced pesticide residue from 44 to $76 \%$, particularly in the cases of tebuconazole and imidacloprid, respectively (Figure 2). This fact is in concordance with several studies that have shown the importance of the fermentation process in residue losses (Navarro et al., 1999; Cabras and Angioni, 2000; Fernandez et al., 2005; Gonzalez-Rodriguez et al., 2009). However, some of these authors did not found effect of malolactic fermentation on quinoxyfen, mepanipyrim, carbaryl, carbendazim, chlorothalonil, fenarimol, metalaxyl, oxadixyl, procymidone, triadimenol or tebuconazol losses (Cabras et al., 1999; GonzalezRodriguez et al., 2009).

Pomace represented the other critical step in which residues were reduced in both white and red wine vinification. Bentonite clarification was additionally important in reducing residues in white wine vinification. The importance of pomace in removing residues was directly related to the pesticide LogKow. Thus, pomace explained over $50 \%$ of tebuconazole, pyrimethanil and buprofezin removal and $100 \%$ of Lambda-cyhalothrin removal. However, for the most hydrophilic compounds, imidacloprid and acetamiprid, this step did not result in a significant effect (Figures 2 and 3). Gonzalez-Rodriguez et al. (2009) found that over $88 \%$ of tebuconazole was detected in pomace and only $12 \%$ at the end of the alcoholic fermentation in red wine. The same results were reported for cyprodinil, fludioxonil, pyrimethanil and quinoxyfen (Fernandez et al., 2005). Other researchers found no residues of triazole fungicides at the end of the alcoholic fermentation in red wine (Cabras and Angioni, 2000).

Clarification with bentonite had an important effect only for buprofezin. Some researchers have observed a strong effect of the clarification 


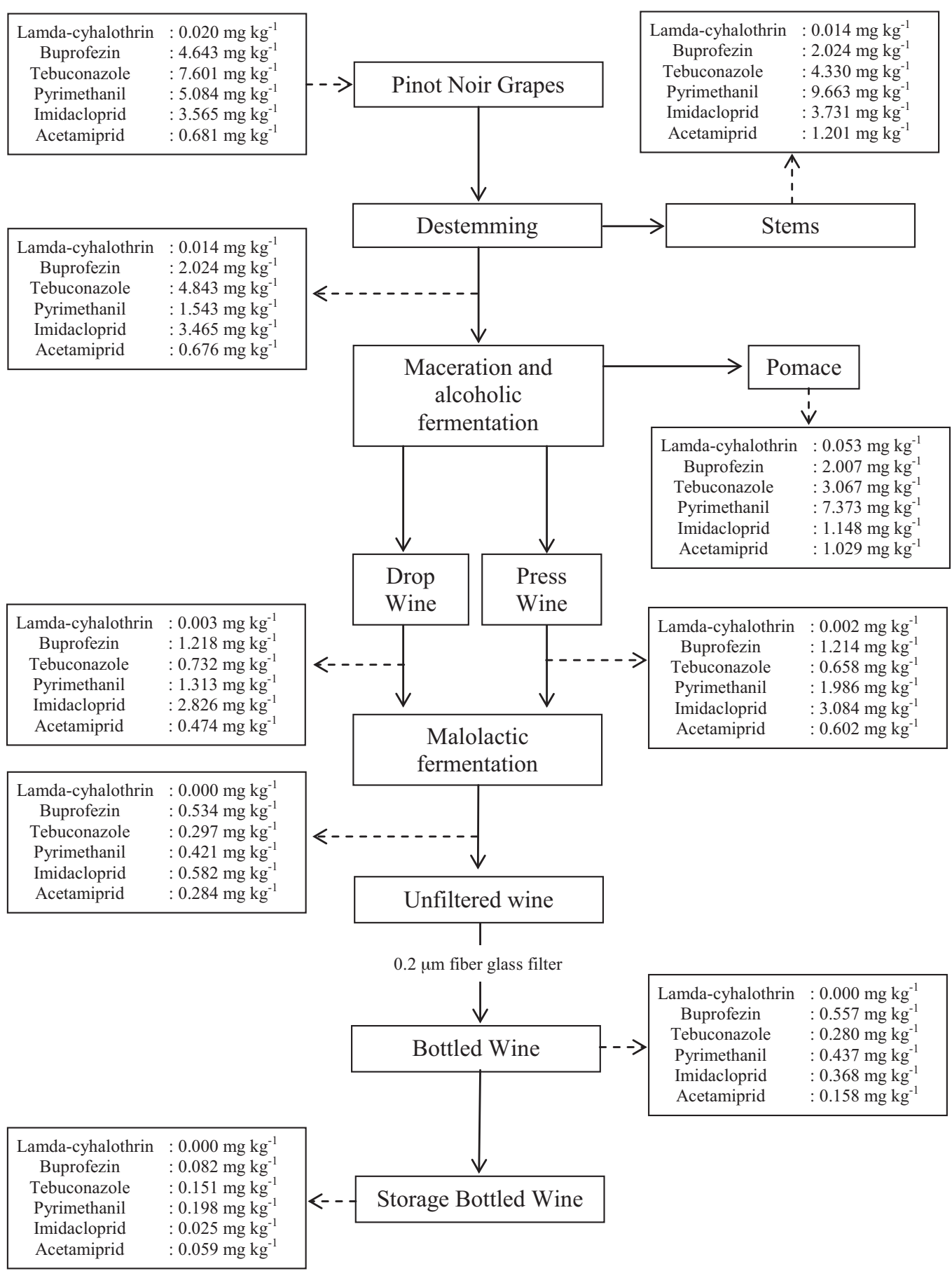

Figure 2. Red wine vinification flow diagram, sample steps and pesticide concentration in each critical stage. Values correspond to the average of two replications. 


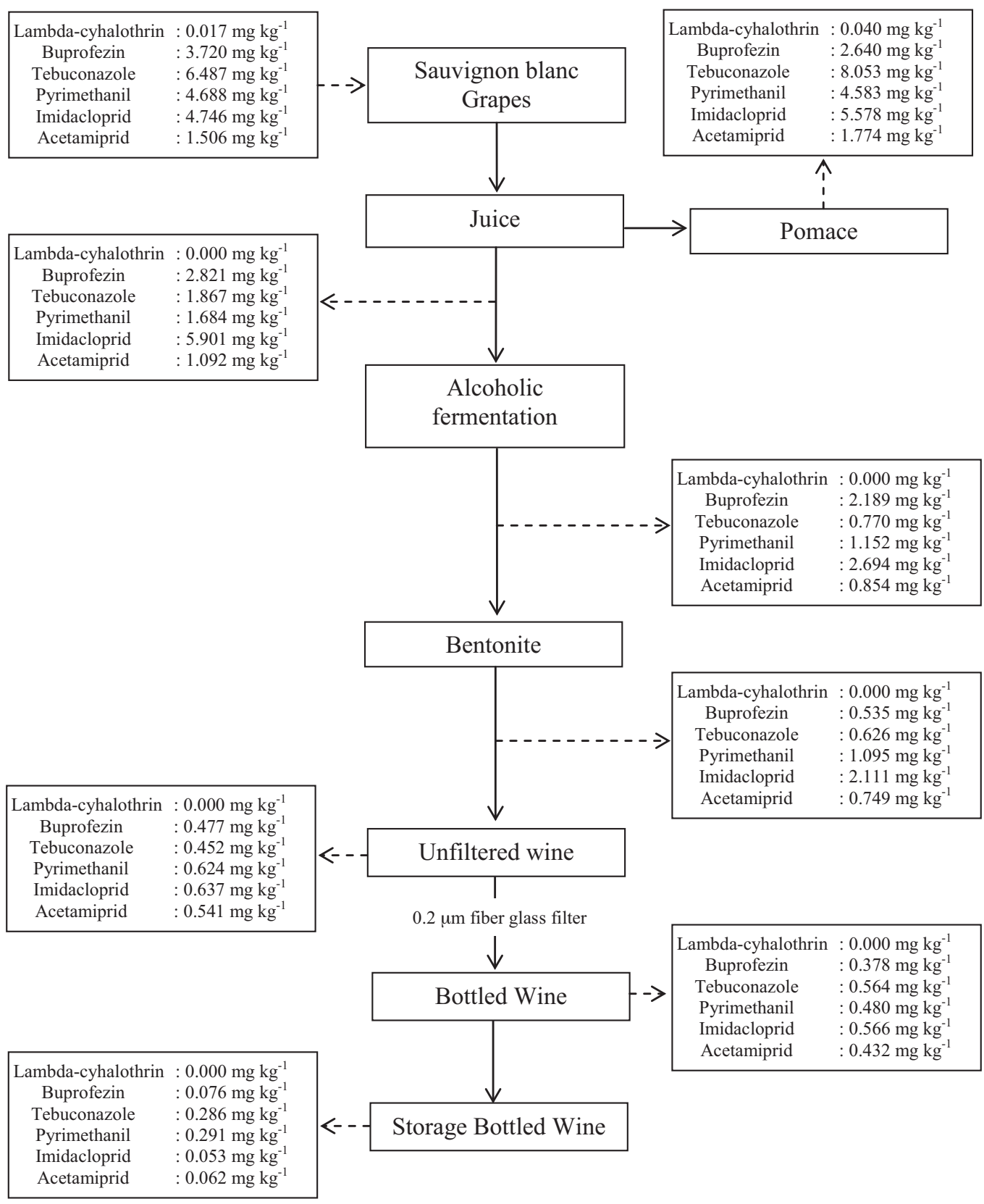

Figure 3. White wine vinification flow diagram, sample steps and pesticide concentration in each critical stage. Values correspond to the average of two replications. 
process in the removal of pesticide residues, but these results are variable depending on the type of pesticide and the clearing substance (Navarro et al., 1999; Cabras and Angioni, 2000; Fernandez et al., 2005; Gonzalez-Rodriguez et al., 2009; Angioni et al., 2011). According to Cabras et al. (1997), bentonite was able to remove only cyprodinil, but not fludioxonil, pyrimethanil and tebuconazole, and charcoal was the only effective clearing substance, as it removed over $90 \%$ of the pesticides. Oliva et al. (2007) did not find a significant effect of bentonite plus gelatin as removal substances for famoxadone, fluquinconazole and trifloxystrobin. Similarly, Likas and Tsiropoulos (2011) were able to remove tebufenozide with charcoal without using bentonite, gelatin, PVPP or potassium caseinate.

Filtration through a fiber glass filter did not show any significant effect on pesticide residue removal in both white and red vinification processes. Contrary results can be found in the literature regardless of filtration and clarification practices used, though results depend on the types of pesticides and matrix (Navarro et al., 1999; Fernandez et al., 2005; Oliva et al., 2007).

Wine bottle storage was also critical in residue dissipation. All pesticides were reduced over $70 \%$ in both red and white wine (Table 3). Limited information exists about the effect of wine storage on pesticide persistence. Navarro et al. (1999) found reductions of fenarimol, vinclozolin, penconazole and metalaxyl residues of approxi- mately $37,31,26$ and 14\%, respectively, after 180 days of storage. Stavropoulus et al. (2001) found rapid degradation of methidation and pyrazophos in red and white wine during bottled storage, with a $\mathrm{DT}_{50}$ of less than 34 days.

According to the results, the pesticide dissipation curves were the same for white and red wine grape berry cultivars and are well described by a firstorder dissipation model. Additionally, dissipation rates were consistent between individual or mixed pesticide treatment and both types of cultivars.

The principal steps in which pesticide residues could be reduced are alcoholic and malolactic fermentations and bottled wine storage. However, residue removal by pomace and/or clarification (bentonite) could be variable, depending on the type of pesticide.

Finally, further understanding of pesticide transfer factors to wine, removal of residues in vinification processes and bottle storage, and pre-harvest intervals for wine grapes are measures that could successfully assure that future wines contain no pesticide residues.

\section{Acknowledgements}

The authors wish to thank FONDECYT (Chilean Fund for Science and Technology) for funding Project Number 1120925 and ANASAC Chile S.A. and SIDAL Ltda. for their support. 


\section{Resumen}

\section{Alister, M. Araya, J.E. Morandé, C. Volosky, J. Saavedra, A. Cordova y M. Kogan.} 2014. Efecto del cultivar, condiciones de aplicación y proceso de vinificación en la disipación de seis plaguicidas en uva vinífera. Cien. Inv. Agr. 41(3):375-386. La presencia de residuos de plaguicidas en productos agrícolas primarios es un tema muy importante para los productores y consumidores, sin embargo la información existente respecto al efecto de las condiciones de aplicación sobre la persistencia de los residuos y su potencial traspaso a productos elaborados es limitada. Durante la temporada 2012, se desarrollaron estudios de campo y laboratorio destinados a determinar la disipación de lambda-cihalotrina, buprofezin, pirimetanil, tebuconazole, imidacloprid y acetamiprid en uva vinífera Sauvignon blanc y Pinot Noir, y la distribución de sus residuos en el proceso de vinificación. La vida media $\left(\mathrm{TD}_{50}\right)$ cuando estos plaguicidas cuando fueron aplicados en forma individual, o cuando fueron aplicados en mezcla de tanque, no presentaron diferencias y su promedio fue de 16,$4 ; 14,0 ; 19,7 ; 26,0$; 14,5 y 13,4 días para lambda-cihalotrina, buprofezin, pirimetanil, tebuconazole, imidacloprid y acetamiprid, respectivamente, sin observarse diferencia en su disipación entre ambos cultivares. Todos los plaguicidas, con excepción de lambda-cihalotrina, fueron traspasados desde la uva al vino, observándose un porcentaje de trasferencia promedio entre un 3 a 23\% en el caso del vino tinto, y de un 9 a 30\% en el caso del vino blanco. Los pasos que lograron una mayor reducción en la concentración de los residuos de plaguicidas en el vino tinto, fueron la fermentación alcohólica, prensado (a través del orujo) y la fermentación malolactica. En el caso del vino blanco fueron el prensado (a través de la uva y raquis), fermentación alcohólica y clarificación con bentonita. Además, en ambos vinos, el almacenado en botellas por diez meses, mostró un efecto importante en la reducción de los residuos de los plaguicidas.

Palabras clave: Carencia, factor de transferencia, residuos, vino.

\section{References}

Angioni A., G. Sarais, F. Dedola, and P. Caboni. 2006. Pyrimethanil residues on table grapes Italia after field treatment. J. Environ. Sci. and Health Part B 4: 833 - 841 .

Arora P., G. Jyot, B. Singh, R. Battu, B. Singh, and P. Aulakh. 2009. Persistence of imidacloprid on grape leaves, grape berries and soil, Bull. Environ. Contam. Toxicol. 82: $239-242$.

Banerjee, K., A. Kumar, P. Adsule, S. Patil, S. Oulkar, and D. Jadhav. 2006. Rate of degradation of L-cyhalothrin and methomyl in grapes (Vitis vinifera L.). Food Aditt. Contam. 23: 994 $-999$.

Cabras, P., A. Angioni, V. Garau, M. Melis, M. Pirisi, E. Minelli. 1997. Fate of some new fungicides (cyprodinil, fludioxonil, pyrimethanil, tebuconazole) from vine to wine. J. Agricultural and Food Chem. 45: 2708-2710.
Cabras, P., and A. Angioni. 2000. Pesticides residues in grapes, wine and their processing products. J. Agricultural and Food Chem. 48: 967-973.

Cabras, P., A. Angioni, V. Garau, M. Melis, F. Pirisi, E. Minelli, F. Cabizza, and M. Pala. 2001. The effect of simulated rain on fopet and mancozeb residues on grapes and on wine leaves. J. Environ. Sci. and Health Part B, 36: 609-618.

Fernández, M.J., J. Oliva, A. Barba, and M. Cámara. 2005. Fugicide dissipation curves in wine-making process with and without maceration step. J. Agric. Food Chem. 53: 804-811.

Gabriolotto, C., M. Monchiero, M. Negre, D. Spadaro, and M. Gullino. 2009. Effectivenes of control strategies against Botrytis cinerea in vineyard and evaluation of the residual fungicide concentrations. J. Environ. Sci. Health B 44: 389 - 393.

González-Rodríguez, G., B. Cancho-Grande, A. Torrado-Agrasar, J. Simal-Gándara, and J. Mazaira-Pérez. 2009. Evolution of tebuconazole resi- 
dues through the winemaking process of Mencía grapes. Food Chem. 117: 529-537.

Gupta, R., S. Gupta, V. Gajbhiye, H. Meher, and G. Singh. 2005. Residues of imidacloprid, acetamiprid and thiamethoxam in gram. Pestic. Res. J. 17: 46-50.

Gupta, S., V. Gajbhiye, and R. Gupta. 2008. Effect of light on degradation of two neonicotinoids viz acetamiprid and thiacloprid in soil. Bull. Environ. Contam. Toxicol. 81: 185-189.

Jun, L., L. HauFei, L. Jing, Z. ZhengYang, and F. MingTao. 2008. Study on the degradation trends of cyhalothrin in apple fruit, J. Fruit Sci. 25: 661 -665 .

Jyot, G., P. Arora, S. Sahoo, B. Singh, and R. Battu. 2010. Persistence of trifloxystrobin and tebuconazole on grape leaves, grape berries and soil. Bull. Environ. Contam. Toxicol. 84: 305 - 310.

Likas, D., and N. Tsiropoulus. 2011. Fate of three insect growth regulators (IGR) insecticides (flufenoxuron, lufenuron and tebufenozide) in grapes following field application and through the wine-making process. Food Adit. Contam. 28: 189- 197.

Lorenzini, M. 2007. Pesticide residues in Italian Ready-Meals and dietary intake estimation, Journal of Environmental Science and Health, Part B. 42: 823- 833

Liu, C., K. Wan, J. Huang, Y. Wang, and F. Wang.2012. Behavior of mixed formulation of metalaxyl and dimethomorph in grape and soil under field conditions. Ecotoxicol. Environ. Saf. 84: 112- 121.

Liang, H., J. Qiu, W. Li, Z. Zhou, F. Liu, and L. Qiu. 2012. Stereoselective dissipation of epoxiconazole in grape (Vitis vinifera cv. Kyoho) and soil under field conditions. Chemosphere 87: 982987.

Mandal, S., S. Das, and S. Bhattacharyya. 2010. Dissipation study of thiophanate methyl residue in/ on grapes (Vitis vinifera L.) in India. Bull. Environ, Contam. Toxicol. 84: 592- 595

Mohapatra, S., A. Ahuja, M. Deepa, G. Jagadish, G. Prakash, and S. Kumar. 2010. Behaviour of trifloxystrobin and tebuconazole on grapes under semi-arid tropical climatic conditions. Pest Manag. Sci. 66: 910 - 915.

Mohapatra, S., A. Ahuja, D. Sharma, D. Deepa, G. Prakash, and S. Kumar. 2011. Residues study of imidacloprid in grapes (Vitis vinifera L.) and soil. Qual. Assur. and Safety of Crops \& Foods 3: 24- 27.

Navarro, S., A. Barba, J. Oliva, G. Navarro, and F. Pardo. 1999. Evolution of residual levels of six pesticides during elaboration of red wines. Effect of wine-making procedures in their disappearance. J. Agric. Food Chem. 47: 264 - 270.

Oliva, J., P. Payá, A. Cámara, and A. Barba. 2007. Removal of famoxadone, fluquinconazole and trifloxystrobin residues in red wines: effects of clarification and filtration processes. J. of Environ. Sci. and Health, Part B. 42: 775-781.

Oulkar, D., K. Banerjee, S. Upadhyay, A. Taware, P. Deshmukh, and M. Adsule. 2009. Degradation kinetics and safety evaluation of buprofezin residues in grape (Vitis vinifera L.) and three different soils of India. Pest Manag. Sci. 65: 183 - 188.

Pasarella, I., I. Elia, G. Guarino, G. Bourlot, and M. Négre. 2009. Evaluation of the field dissipation of fungicides and insecticides used on fruit bearing trees in northern Italy. Journal of Environmental Science and Health, Part B 4: 137- 143.

Stavropoulus, P., P. Athanasopoulus, and N. Kyriakidis. 2001. Degradation of pyrazophos and methidation in fortified red and white wine under conditions of light and darkness. Food Chem. 72: 473-477.

Thorbek, P., and K. Hyder. 2006. Relationships between physicochemical properties and maximum residue levels and tolerances of crop-protection products for crops set by the USA, European Union and Codex. Food Addit. Contam. 23: 764- 776. 